\title{
Genetic Testing and Insurance: The Case for Regulation
}

\section{Margaret Otlowski}

$\mathrm{T}$ There is currently a significant level of debate in Australia and other jurisdictions about the appropriateness of intervention in the private insurance market to regulate the use of genetic test information by insurers. Whilst the issue has arisen most directly with the emergence of genetic testing, concerns appear to be extending to the use of any predictive genetic information for risk assessment purposes. Indeed, questions are currently being raised about insurers' use of family history information which is a source of information insurers have historically always had access to.

In response to concerns about the use of genetic information, in August 2000, the Commonwealth Government established an Inquiry into the Protection of Human Genetic Information to be jointly conducted by the Australian Law Reform Commission and the Australian Health Ethics Committee of the National Health and Medical Research Council. Pursuant to this Inquiry, a Discussion Paper has recently been released which contains proposals for reform, amongst other things, covering the circumstances in which insurers can use genetic test information (Australian Law Reform Commission, 2002).

The aim of this paper is to look at some of the problems associated with insurers' reliance on genetic information for underwriting purposes and to present the case for regulation (although not necessarily through legislative means). The main source of contention in relation to insurers' use of genetic information appears to lie in the field of predictive genetic test information: that is, in the situation where the individual is asymptomatic and the testing indicates that he/she is predisposed to developing a genetically related disease in the future. Predominantly, this contention is caused by limitations of the predictive value of such tests - usually only indicating that a person is at increased risk of developing a genetic disease, there being no certainty about this issue.

It should be made clear from the outset that the scope of this paper is limited to those forms of voluntary insurance for which underwriting on health grounds is undertaken, such as life insurance, sickness and critical illness insurance: in the Australian context at least, this does not include health insurance for which a system of community rating is statutorily mandated pursuant to the National Health Act 1953 (Cth). Further, it should be noted that the paper is written primarily from a legal perspective. Clearly, economic efficiency implications would also need to be fully considered by policy makers.

Margaret Otlowski is Associate Professor of Law, The University of Tasmania. 


\section{The Legal Framework}

The current legal framework can be simply stated as there is no doubt that insurers are legally entitled to have access to genetic test results, and to take these into account for the purposes of underwriting for life and related forms of insurance. Contracts of insurance are contracts 'uberrimae fidei' — of the 'utmost good faith'. This terminology describes a class of contracts, including insurance contracts, in which one party has a duty to disclose material facts relevant to the subject matter to the other party. In the insurance context, this requirement reflects the reality that applicants for insurance usually know more about their risk factors than the insurance company. The common law (now codified in the Insurance Contracts Act 1984 (Cth) s 21(1)) therefore imposes an obligation to make full disclosure of all information material to the insurers' assessment of risk, which a reasonable person in the circumstances could be expected to know to be a matter which is relevant, in order to ensure that there is symmetry of information between the applicant and the insurer. Failure to make the required disclosure may result in the contract being invalidated (see Part IV, Div 3 Insurance Contracts Act 1984 (Cth) which deals with both innocent and fraudulent non-disclosures).

The important role that commercial insurance plays in our society is reflected in the fact that insurers are given an exemption from disability discrimination under Commonwealth and State/Territory anti-discrimination legislation. The exemption from disability discrimination recognises that the whole notion of insurance is premised on treating individuals differently, based on principles of risk assessment which have regard to their health status, and that insurers routinely engage in conduct which would otherwise constitute unlawful discrimination.

The relevant Commonwealth legislation is the Disability Discrimination Act 1992 (Cth) which would apply to insurers operating in Australia, except for those who conduct business solely within a State and therefore would come within the scope of the State and Territory legislation (see s 12(11)(b)). The term 'disability' is defined broadly (see s 4)) as including a disability that presently exists, that may exist in the future, or one that is imputed to a person. Together with the wide definition of discrimination (essentially to mean less favourable treatment: see $\mathrm{s}$ 5), there is little room for doubt that this legislation would cover discrimination on the basis of genetic test information where that information discloses that the person may in the future develop a particular genetic disease.

The legislation is framed so that prima facie, disability discrimination in insurance will be unlawful, and if challenged, the onus would lie on the insurer to affirmatively establish that the relevant discrimination on the grounds of disability came within the insurance exemption. This is clear from the High Court decision in Australian Mutual Provident Society v Goulden and Others (1986) 160 CLR 330 in the context of interpreting the former Anti-discrimination Act 1977 (NSW). The operation of the exemption is qualified by the requirement that insurers must be able to justify their decisions on the basis of actuarial or statistical data on which it is reasonable for the insurer to rely, or in the absence of such data, that the discrimination is reasonable having regard to other relevant factors. The key 
provision in the Commonwealth Act is s 46 covering both discrimination in the form of refusal to offer insurance or discrimination in respect of the terms or conditions on which insurance is offered, and the provisions of most State and Territory anti-discrimination Acts are in similar terms.

The Disability Standards and Guidelines: Guidance for Providers of Insurance and Superannuation of the Human Rights and Equal Opportunity (1998), which seek to give some general guidance on the operation of the exemption, are relevant to its interpretation. Amongst other things, the guidelines spell out what is unreasonable for insurers to have regard to. In particular, the guidelines state that it is not reasonable - and therefore unlawful - for an insurer to: refuse to insure a person with a disability because the insurer does not have any data or there is little data or statistical information available; or to refuse to insure a person with a disability because of historical practice; or to make inaccurate assumptions about people with a disability.

The guidelines specify that statistical or actuarial data should be considered if it is available or reasonably obtainable. This includes data from sources that the industry uses domestically and internationally, including underwriting manuals, local data, relevant overseas studies, and domestic and international insurance experience. Further, the guidelines provide that in the absence of statistical or actuarial data, the decision to discriminate must be shown to be reasonable because of other relevant factors, eg medical opinion, opinions from other professional groups, actuarial advice or opinion, relevant information about the individual seeking insurance, and commercial judgement.

The precise scope of the exemption in the context of genetic test information is presently untested as there have been no cases alleging genetic discrimination before the Human Rights and Equal Opportunity Commission or State and Territory anti-discrimination tribunals. There has, however, been a recent case involving interpretation of the equivalent provision in the Sex Discrimination Act 1984 (Cth) s 41 which has highlighted the importance of there being actuarial or statistical data from a source on which it is reasonable for the insurer to rely (see $D$ and A Registered Life Insurer 11 February 2000, a decision of Commissioner McEvoy of the Human Rights and Equal Opportunity Commission.)

\section{The Practical Context}

By virtue of the established practice of insurers seeking and taking account of genetic information from family history, the life insurance industry has long been involved in a form of genetic underwriting. Clearly, however, the increasing availability of predictive genetic test information presents a new, and potentially more accurate source of data. Due to the relative novelty of this form of information and the long time-lag in the actuarial tables reflecting new developments, there has been little experience in Australia in underwriting based on genetic test information. As noted, there is no doubt that for the purposes of risk assessment, insurers are legally entitled to take into consideration, genetic test information disclosed by an applicant, subject only to the constraints imposed by 
anti-discrimination legislation (that is, the insurers have relevant actuarial or statistical data on which it is reasonable to rely, or, in the absence of such data, the discrimination is reasonable having regard to other factors).

The peak insurance body, Investment and Financial Services Association Ltd (IFSA) has commissioned the Institute of Actuaries of Australia to undertake periodic surveys on the use of genetic tests by insurers. To date, three six monthly surveys have been reported: the first for the period ending $31^{\text {st }}$ May 2001; the second covering the period $1^{\text {st }}$ June- $30^{\text {th }}$ November 2001 , and the third for the period $1^{\text {st }}$ December 2001-31 $1^{\text {st }}$ May 2002 (Institute of Actuaries of Australia, 2002). From the industry's own data, it is known that the use of genetic test results, in some instances, leads to the denial of insurance, or the offering of insurance on non-standard terms. For the entire data collection period, 174 applications were received which disclosed a positive genetic test result. Of these applications, which were across a range of life insurance products, 70 were accepted on standard terms, 45 were accepted on non-standard terms, 16 were deferred and 25 were declined. (Underwriting was not yet complete at the time of the survey for the remaining applications.)

Insurance application forms have always included questions about family history, tests undertaken etc. Some of the questions contained in some recent application policies appear to be more searching, for example, whether the applicant is considering to undergo any medical test or procedure, or whether they have been advised by their medical practitioner to do so. This new approach appears to be aimed at discouraging individuals from taking out life or related forms of insurance prior to undertaking testing, although one might question why this is in any event perceived to be problematic, given that the individual at this point in time does not know more than the insurer about the outcome of that test, and presumably any family history or other health information leading to the test being considered would, in any event, need to be disclosed (Otlowski, 2001).

The position of insurers in relation to genetic test information, in particular, their vigorous defence of the industry's right to use this information, has been clearly stated in IFSA's Policy on Genetic Testing. This policy, developed initially as a voluntary industry code, now takes the form of an industry standard which converts the policy from guideline status to a mandatory standard for IFSA members (IFSA, 2002).

It has been argued on behalf of insurers that genetic test information is no different from other medical information which they seek and that, in any event, they have, for decades, already been using genetic information through family history. For the most part, insurers' arguments defending their access to and use of genetic test information centre on fears about 'adverse selection' - the tendency of individuals to take out or increase their insurance or coverage more than they would otherwise when they are aware of their higher than average risk status. Insurers argue that individuals with a high or increased risk of a genetic disease may have an incentive to insure their lives and incomes for high values, leaving insurance companies vulnerable to large pay-outs if they are not entitled to gain access to the genetic test information available to the applicant. 
Further, it is argued that if there is a disproportionately high number of highrisk individuals amongst the insured population, the level of claims will increase, thereby increasing the cost of life insurance for the majority. This, in turn, would reduce the number of low-risk people prepared to pay for cover, with people on lower incomes most likely to be affected. In this context, equity considerations have also been raised in support of life insurance companies having access to all information relevant to risk. It has been argued that adverse selection works to the advantage of those who ignore their obligations and to the disadvantage of those who do not, and that measures must be taken to deter this practice which discriminates against existing policyholders. On this basis, it is contended that the results of genetic tests should be treated no differently to any other information relevant to the assessment of risk. (For further analysis and critique of the insurance industry position, see Otlowski, 2000:201-208)

Consumer groups representing people who are at genetic risk, and related organisations such as the Human Genetics Society of Australasia, have urged that genetic test results be viewed in their wider context, in particular, taking account of the fact that people who are identified as being at greater risk due to positive genetic tests may initiate preventative measures which reduce that risk. In response, the IFSA policy on genetic testing was amended and now states that 'when assessing the overall risk associated with a particular genotype, insurers will take account of any special medical surveillance that may be beneficial, early treatment and the likelihood of successful treatment' (IFSA, 2002:10.5).

There have been a number of other positive developments. The current IFSA policy is that insurance companies in Australia should not require genetic testing as a precondition to insurance. In particular, clause 2 of the IFSA Policy on Genetic Testing states 'insurers will not initiate any genetic tests on applicants for insurance.' This position, not to initiate genetic testing, accords with international instruments which highlight the importance of voluntary consent and require that individuals are not coerced into genetic testing: for example, the Council of Europe Bioethics Convention, 1996 Articles 5 and 12 and Explanatory Memorandum 1997; the World Health Organisation Proposed International Guidelines on Ethical Issues in Medical Genetics and Genetic Services 1997; and the United Nations Educational, Scientific and Cultural Organisation, Universal Declaration on the Human Genome and Human Rights 1997 Article 5.

Related to this is the fact that insurers have agreed not to offer cheaper rates to those with 'good genetic test results,' to avoid possible indirect pressure to undertake testing. This is clear from clause 4 of the IFSA Policy on Genetic Testing which states 'in order to prevent indirect coercion to undergo genetic tests, insurers will not use genetic tests as the basis of preferred risk underwriting (offering individuals insurance at a lower than standard premium rate).' However, because of the potential anti-competitive effect of this and other clauses of the draft policy, it had to be submitted for approval to the Australian Competition and Consumer Commission. It was ultimately given authorisation in November 2000 for a period of two years, although only after some amendments to the original application, and lobbying from consumer groups and other stakeholders who 
supported these clauses as a means of avoiding inappropriate incentives being given to individuals to undergo genetic testing.

The new IFSA standard now contains a requirement that people must be given reasons for underwriting decisions. However, it is not clear as yet what this requires in practice, in particular, whether it extends to details of the actuarial, statistical, or other data relied on by the insurance company in reaching its decision. Under s 75 of the Insurance Contract Act 1984 (Cth), individuals can request in writing that they be given written reasons. There are, however, questions about the scope of this provision, and whether it would entitle an individual to details of the actuarial, statistical, or other data relied upon. At present, the only way of obtaining this information is to lodge a complaint under the Disability Discrimination Act 1992 (Cth) invoking the powers of the Human Rights and Equal Opportunity Commission to require full disclosure: if disability discrimination proceedings are commenced under s 107(1) of that Act, the Human Rights and Equal Opportunity Commission has the power to require a person who is prima facie in breach of the prohibition of unlawful discrimination to disclose to the commission the source of the actuarial or statistical data on which the act of discrimination was based.

So far as appeals are concerned, where an applicant for insurance is aggrieved about a decision affecting him or her, they may take the matter up with the internal complaints body within the company, and in practice, decisions are regularly challenged. (It is now a requirement under the IFSA Standard that insurers will have a competent and efficient internal dispute resolution system to deal with complaints relating to underwriting decisions involving a genetic test result.) However, the options presently available to an aggrieved individual beyond this are limited. Although there is a Financial Industry Complaints Service (an Ombudsman type body sponsored by the industry), a wide range of matters are expressly excluded from its jurisdiction, including complaints about the level of premium, underwriting or actuarial factors resulting in an offer of insurance on non-standard terms, or underwriting or actuarial factors leading to the rejection of a proposal for commercial or medical reasons. Currently, therefore, there is no independent industry appeal mechanism for complaints in respect of the use which is made of genetic test information. The only choice aggrieved individuals have is to bring proceedings for disability discrimination under anti-discrimination legislation, and this option has not yet been used. The creation of an intermediate level of appeal, more accessible than the formal legal avenues, is one of the proposals put forward by the current Inquiry in its Discussion Paper (Australian Law Reform Commission, 2002:620-627).

\section{Arguments for Regulation}

One of the arguments advanced in support of regulation is that allowing insurers access to genetic information will have the effect of decreasing the availability of insurance. Individuals may be excluded outright from buying insurance due to their genetic status; limited in the coverage that they can obtain; 
or forced out of the market altogether due to unacceptably high premiums. The fear is that this will result in a 'genetic underclass' which is uninsurable, and as already noted, there is evidence in Australia of individuals being rejected by insurers, or otherwise disadvantaged because of their genetic status. This, in turn, raises questions about the social function of insurance, and whether it is acceptable that certain individuals may be precluded from access to insurance due to their genetic make-up. Put another way, the question needs to be asked where the burden of the risk should lie: is it fairer to expect all those who take out life insurance to subsidise this risk if insurers are prevented from factoring this into their risk assessment, or should the risk lie with the genetically vulnerable individual, and ultimately the state through social security protection? It must be remembered that life and income protection insurance such as sickness and disability insurance operate on commercial principles, and that individuals may be lawfully discriminated against on the basis of their health status (eg high blood pressure). This gives rise to the question - is it justifiable to differentiate genetic test information from other medical information?

The unique and sensitive nature of genetic information has been put forward as a reason for denying insurers access to genetic test data. It is argued that such information is intensely personal and highly confidential and that once particular genetic information has been identified in an individual, it represents an irreversible biological marker (Brom, 1991:141). Moreover, because of the very nature of genetic test information, it discloses information not only about the individual upon whom the test has been undertaken, but also about members of that individual's family. Arguments based on the 'uniqueness' of genetic information have, in turn, been countered with claims that 'genetic exceptionalism,' that is, inappropriately singling out genetic conditions for special treatment, should be avoided. Whilst debate continues about the appropriate status of genetic information, it seems difficult to dispute that this form of information has certain characteristics which call for careful protection.

Another concern that has been raised regarding insurers' access to genetic test information is that at-risk individuals may be deterred from undertaking necessary genetic testing. The fear is that individuals who, in the light of their family history, may be at risk of developing a genetic disease may decline to be tested, knowing that if they are definitely found to be have the relevant gene, they may be completely denied insurance. This disquiet is particularly well-founded in circumstances where early knowledge of a condition or predisposition to developing a disease may play a significant role in treatment. One example is the condition familial adenomatous polyposis - an autosomal, dominantly inherited condition, which usually leads to cancer. Those at risk of developing the condition are recommended to attend for regular sigmoidoscopic surveillance to determine whether any of the hallmark bowel polyps develop. Genetic testing is now available for this condition which would establish whether or not such surveillance, which involves an invasive and costly procedure, is required. However, fears have been expressed by health care professionals in this field that permitting insurers to use genetic test information will impose significant barriers 
to genetic testing in these at-risk families which may have ramifications for individual health and well-being, given the potentially life-saving nature of this form of testing.

There is also the related concern that individuals will be unwilling to participate in genetic testing for research purposes because of fear that they will be disadvantaged by such participation, thus possibly jeopardising the success of such research endeavours. A study by the Office of Technology Assessment of the US Congress reported that some who participated in screening programs and were found to be carriers of sickle cell trait (who would not themselves be affected) nevertheless experienced discrimination at work and from insurance companies that raised their premiums (Nuffield Council on Bioethics, 1993:7.21).

A number of studies have been undertaken to examine the incidence of genetic discrimination and the circumstances in which it occurs (Billings et al, 1992; Lapham, Kozma and Weiss, 1996; Geller, et al 1998; Low, King, and Wilkie, 1998; Wertz, 1998). The results of many of these studies point to instances of misinterpretation and misunderstanding of genetic test information, with the consequence that decisions are being made which are prejudicial to the individual's interests in circumstances where that is not justified on an objective view of the evidence. For example, there have been instances where individuals have been discriminated against in their access to insurance purely on the basis of a genetic label arising from a positive gene test, without regard to the actual manifestation of the condition for that individual - what has been described as the 'problem of variability' (Billings et al, 1992:479). Additionally, there have been instances of discrimination in the US directed against healthy carriers of recessive genetic conditions (Billings et al, 1992:478). There is, furthermore, evidence of genetic discrimination from the United States in relation to sickle cell screening undertaken during the 1970s.

There has also been some anecdotal evidence from the United Kingdom of misunderstandings of genetic test information. The Human Genetics Advisory Commission noted in its 1997 Report that it had 'received compelling evidence of unreasonable discrimination, due probably to misunderstanding of genetics, but no hard evidence that this was systematic, nor a clear idea as to whether it was rare or quite common' (Human Genetics Advisory Commission: 1997:3.11). A study of genetic support groups found that people in three subgroups which represented no adverse actuarial risk to insurers on genetic grounds reported problems in obtaining life insurance: healthy carriers of recessive genetic or sex limited conditions; healthy non-carriers of genes for late onset disorders; and parents of children whose condition is the result of spontaneous mutation. This included instances of some carriers of childhood onset conditions such as Duchenne muscular dystrophy and cystic fibrosis being mistakenly treated by insurers as if they had the disease (Low, King, and Wilkie, 1998:1634). The conclusion of the researchers was that confusion and ignorance in interpreting genetic information are central to the problem of genetic discrimination.

There is no reason to suppose that the situation would be different in Australia. Indeed, the potential for decisions being made by insurers without a 
legitimate basis is illustrated by the practice of some Australian insurers in relation to the use of HIV/AIDS exclusion clauses in automatic acceptance superannuation funds. Because of complaints that had been made about the discriminatory nature of such clauses, an independent firm of consultants was commissioned by the Commonwealth Government to examine their use and to ascertain whether there was valid actuarial or statistical evidence supporting the concerns of the industry. The resulting report (Trowbridge Consulting, 1993), found that the clauses used were unjustified and illegal under the Disability Discrimination Act 1992 (Cth).

This experience suggests that fears about misuse of genetic test information by insurers are probably not misplaced. Indeed, there have been documented reports of alleged genetic discrimination by insurers in a study published in the Journal of Law and Medicine (Barlow-Stewart and Keays, 2001). The authors identified a total of 48 cases of alleged genetic discrimination, virtually all in the insurance context. All of these cases affected individuals who were in good health and where the adverse treatment was believed to be a direct result of the predictive genetic test result.

Genetic discrimination was reported with respect to genetic tests for a wide range of conditions including, haemochromatosis, inherited predisposition to cancer (breast, bowel, melanoma) neurological degenerative disorders such as Huntington's disease and early onset Alzheimer's disease. In the area of insurance, which involved by far the majority of cases, discrimination was reported in accessing a wide array of insurance packages and types following disclosure of a positive genetic test result (which, as noted earlier, applicants are required to disclose at the point of taking out insurance or if they seek to raise their level of cover.)

The discrimination was alleged to have taken various forms. In some cases, it resulted in premiums being loaded when the individuals sought to increase their level of cover (eg two individuals who had undergone genetic testing for haemochromatosis); in some cases, applications for increased cover were rejected (eg in the case of some individuals with inherited predisposition to cancer or neuromuscular and connective tissue disorder). There were few outright rejections, but notably, the majority of the respondents ( 29 out of 48 , or 60 per cent) had reported taking out life and income protection insurance prior to having the genetic test. Quite a few of the individuals affected (17 in total) had sought to appeal within the company against the discriminatory condition imposed by the insurance company: only one did so successfully. Notably, however, no individuals reported appealing through existing legal avenues: the majority stating that it was all too hard and stressful and, in some cases, it being reported that they did not know how to seek redress.

It must be acknowledged that there are limitations with this research because of its reliance on unverified accounts (anonymous reports provided to the researcher with limited or no opportunity for any follow up with the person alleging discrimination). Indeed, the authors themselves are very careful to state that these are simply 'alleged' or 'reported' cases of genetic discrimination. Furthermore, it is difficult to discern from the limited information available the 
precise legal status of the insurers' decision in these cases, in particular whether or not the discrimination would have been justified under the insurance exemption and therefore lawful. However, the study authors were of the view that at least some of these cases involved unlawful discrimination under the present disability discrimination legislation.

It should be noted that further empirical research funded by the Australian Research Council is currently being undertaken on a national scale into the nature and extent of genetic discrimination in Australia (Otlowski, Taylor and BarlowStewart, 2002). A key feature of the project is its triangulated design, seeking to gain the experience and perspective of all key stakeholders. In particular, data will be gathered amongst: 'consumers' (those considered to be at risk as a result of a genetic test result or because of their family history); third parties comprising insurers and employers (these being the groups against which allegations of genetic discrimination have most frequently been made); and also through the various organisations within the legal system through which complaints of genetic discrimination may be pursued, with a view to ascertaining whether any cases of genetic discrimination have been recorded. An important aspect of this project will be the verification stage whereby, with the explicit consent of those involved, individual allegations of genetic discrimination will be followed up with the relevant third party. It is anticipated that this process of verification will elucidate factors associated with genetic discrimination from both consumer and third party perspectives, allowing for objective assessment in relation to the legality of the conduct and providing an opportunity for integrated analysis. This project is due to be completed by December 2004 and is expected to establish baseline data against which the success of any future reforms such as those proposed by the joint national Inquiry into the Protection of Human Genetic Information in its Discussion Paper (Australian Law Reform Commission, 2002), can be assessed.

Given the limited terms of the exemption for insurers under current laws, and the need for them to be able to justify what would otherwise be unlawful discrimination, there is no doubt that underwriting decisions that are disadvantageous to the applicant and which are based on a misinterpretation of genetic test information, would amount to unlawful discrimination. Thus, individuals would, in these circumstances, have some remedy pursuant to antidiscrimination legislation, although in practice, as already noted, this option does not appear to have been taken up. One cannot at this stage be certain why this is so, but indications are that factors such as cost, stress, fear of exacerbating the sense of stigmatisation, and in some cases, lack of awareness about legal remedies probably play some role, although as noted earlier, this latter aspect is now being addressed through the IFSA Standard.

Further, it should be acknowledged that it is difficult for individuals to establish that insurers have misinterpreted their genetic test information: they may not be aware that it has occurred, or even if they suspect it has, they are unlikely to have enough information to assess the situation. For this reason, having the option of challenging insurers' use of genetic test data under disability discrimination legislation is arguably not an adequate response. For one thing, as previously 
observed, there has been a notable lack of use of such formal legal remedies in practice. But even more significantly, anti-discrimination legislation deals with the problem of discrimination once it has occurred, after the damage has already been done. There is a case for arguing that it is better to anticipate these problems and put strategies in place to avoid the risk of unfair discrimination. This would also be a much safer option in the light of the sensitive nature of this information and related privacy concerns.

The most compelling argument against allowing insurers unrestricted access to genetic test information is based on the limited predictive value of genetic tests. Little is known about the way in which genetic data is factored into the underwriting process to calculate risk assessment and the cost of premiums. There are, however, reasons to believe that there is real potential for problems to arise. The predictive value of genetic testing varies considerably, depending on the nature of the condition being tested for. In the case of single gene disorders, tests may predict that a disease will probably manifest at some time in the future, however, due to variable expressivity and incomplete penetrance, it will not be possible to predict accurately the point when the condition will begin to reveal itself and the severity with which the person will be affected.

The outcomes of testing for complex or multifactorial disorders, which in practice are the more common genetic conditions, are even less certain as such tests can only identify predisposition to disease, thus changing probabilities but by no means establishing conclusively that the person will in fact develop that condition. The concern is that in a society where a fairly deterministic approach is taken to genetics, if insurers are permitted to use this information for the purposes of risk assessment, it will be credited with greater probative value than it warrants.

It has to be understood that a genetic test result does not, of itself, have actuarial significance. Additional statistical information is required linking a given test result to the occurrence of some disorder in order for a sound prediction of disease or of lowered life expectation to be made: without this additional information which connects genetic test results and the incidence of disease or death, these results lack actuarial import (O’Neill, 1998:721). Establishing relationships between genetic indicators and the economic costs of the risks identified is a painstaking process which must developed separately for each genetic condition. It requires population based research, which optimally should be undertaken within whole national populations to take account of local variations. For this reason, some commentators within the field of clinical genetics have cautioned that it will be many years, quite possibly decades, before an accurate picture emerges (Holtzman et al, 1997).

The complexity of evaluating the 'risks' associated with positive gene tests is compounded by the fact that account needs to be taken of the availability and effectiveness of any treatment which may operate to reduce the level of risk. It has been predicted that once genetic information is properly understood, it will probably have significantly less impact on risk assessment than is currently thought to be the case. Indeed, there have already been some revisions of initial assessments of risk in respect of the BRCA1 test for breast cancer, with original 
estimates of risk being significantly reduced once population based studies were undertaken. In this light, a case can certainly be made that there is presently insufficient reliable evidence regarding the extent to which genetic test results can be used to predict life expectancy or onset of ill health, and that it is therefore impossible for insurers to be in a position to use this information accurately.

A recent report of the United Kingdom House of Commons, Science and Technology Committee (House of Commons, Science and Technology Committee, 2001) expressed dismay at the situation then prevailing in the United Kingdom. At that time, the official policy was that insurers would only use those predictive genetic tests for underwriting purposes which had been approved by the Genetics and Insurance Committee (GAIC) - a committee of experts established to monitor and regulate insurers' use of genetic tests and in particular, to determine which genetic tests have sufficient actuarial relevance to justify insurers' reliance on those test results. However, in practice, there appeared to be considerable uncertainty, even within the industry, about what its policy is regarding the use of genetic test information. One of the telling conclusions of the Science and Technology Committee was that 'it does not appear to be certain, at present, that the information obtained from positive genetic tests is relevant to the insurance industry' (House of Commons, Science and Technology Committee, 2001: para 32). The report pointed to the fact that four of the tests that the Association of British Insurers had recommended insurers use three years ago are now regarded as no longer relevant or reliable. The committee heard evidence that the tests for familial adenomatous polyposis and hereditary motor and sensory neuropathy are irrelevant to insurers owing to the typically early onset of these conditions; the test for myotonic dystrophy is not sufficiently predictive, and multiple endocrine neoplasia has too wide an age of onset. It was suggested that 'this casts the gravest possible doubts on the validity of all the tests not explicitly approved by the Genetics and Insurance Committee ' (House of Commons, Science and Technology Committee, 2001: para 33) which at that stage had only approved the test for Huntington's disease. The committee accordingly expressed its firm view that insurers have given the test results a predictive significance that cannot, at present, be justified.

The committee did note that it is the policy of a number of British insurance companies to only take account of negative test results in the calculation of premiums. Significantly, the committee urged that other companies also consider adopting this approach on the grounds that the scientific and actuarial evidence currently available seems to indicate that 'this is the only justifiable use that can currently be made of genetic test results' (House of Commons, Science and Technology Committee, 2001:paragraph 40). The concerns expressed by this committee about the unreliability of genetic test information (echoing also previous inquiries undertaken in the United Kingdom) led it to recommend that no predictive genetic test result should be used by insurers for the purposes of underwriting, with the exception of negative genetic test results. In the wake of this recommendation, an agreement has been negotiated between the British government and the Association of British Insurers for a moratorium on the use of 
predictive genetic test information by insurers for a five year period, even exceeding the two years that the Science and Technology Committee had recommended. This agreement covers all but the largest quantities of insurance, enabling consumers to obtain up to $\$ 500,000$ of life insurance and $\$ 300,000$ of critical illness, income protection and long term care insurance, without having to disclose any genetic test results. For policies in excess of these amounts, insurers would be entitled to use genetic test results for underwriting purposes, but only those authorised by GAIC (the situation which had prevailed for all policies prior to the moratorium).

\section{Conclusions on Arguments for Regulation}

Although clearly there are limitations to our present knowledge of the extent of genetic discrimination, it is submitted that enough is known of its nature already to determine that there is a problem. Moreover, the extent of the 'problem', if unaddressed, is likely to increase in terms of the number of people affected because of the inevitable expansion in the uptake of genetic tests. The dangers associated with insurers' use of predictive genetic information are too great, at least at the present time, for routine use of genetic information in underwriting. This information should not be used until such time as there is better understanding of its significance, particularly in relation to multi-factorial disorders. In this case, treating genetic test information differently is justified as a response to an identified problem.

The risk of doing nothing has to be weighed up against the risks of intervention: this requires attention to be focused on the nature of the harm in each case and on whether anything can be done about it. Most would agree that individuals in these circumstances are already vulnerable and in a weaker position compared to the insurer who has the capacity to spread the increased risk, if necessary, passing it on to consumers through an increase in premiums. Further, there are ways of protecting insurers from the risk of adverse selection by imposing a financial ceiling, such that for large policies, disclosure of genetic test information would still need to be made, at least for genetic tests for which there was some consensus about their actuarial relevance. This can be justified on the basis of evidence from statistical modeling which shows that the real risk for insurers with regard to adverse selection would be in respect of very large policies, and that the costs to insurers in the case of small to medium sized policies would not be significant (Harper, 1997:1066; Macdonald 1997:1074; Macdonald:1999). It may, however, be necessary to distinguish between life and other forms of personal insurance such as disability or critical illness insurance, as there are indications that the effect of adverse selection arising from the applicant's knowledge of genetic test information could be more severe in relation to such other categories of insurance (Macdonald, 1997:1069; Pokorski and Ohlmer 2000:146). A number of reasons can be put forward to explain this. Gene analysis is likely to be a better predictor for disability than the age at which a person is likely to die. Further, there are far more conditions that result in 
disability rather than death, and pay-outs may be large if over an extended period. However, the key factors appear to be that the use of asymmetrical information has a greater potential to influence purchasing decisions in respect of these products than in the case of life insurance (Pokorski and Ohlmer 2000:146). Moreover, the market for critical illness insurance and related products is more price sensitive, in that a given price increase in insurance causes a greater decrease in the quantity of critical illness insurance purchased as compared with life insurance. Any reform model would need to take these differences into account to ensure that insurers are given adequate protection from the risks of adverse selection.

\section{What Needs to be Regulated?}

If we assume that a need for some intervention in the private insurance market to regulate access to and use of genetic information is accepted, this in turn leads to a number of further questions: where exactly should regulation be targeted and what form should it take? It is important that any intervention take into consideration the competing interests (those of consumers and also the industry's concern about adverse selection) and that it is limited to those areas which currently present a difficulty.

It is therefore necessary to engage in some line drawing to determine the limits of intervention. Firstly, in light of the comments made at the outset of this paper, the focus here is on those forms of voluntary insurance for which underwriting on health grounds is undertaken, such as life, sickness or critical illness insurance. Further, intervention should be limited to predictive genetic tests in circumstances where the individual is healthy and free of symptoms. Indeed, there is no real debate about the entitlement of insurers to use genetic test information where the individual is already suffering symptoms of the condition - or what can be described as diagnostic genetic testing.

A more difficult issue arises with regard to family history: a form of genetic information that insurers have long had access to. Because of the current debate about insurers' access to and use of genetic test results, insurers' use of family history information has now also come under scrutiny. In the United Kingdom, the moratorium only extends to genetic test information, leaving insurers free to continue to draw on family history for underwriting purposes (but a negative genetic test may be used to counter unfavourable family history.) However, the Human Genetics Commission which has been examining the issue of insurers' utilisation of genetic information, had flagged in its Interim Recommendations the status of family history as a troublesome issue which requires attention. The commission expressed its concern 'that the principles of utmost good faith and full disclosure seem to fall most heavily on the consumer' and that 'Few people are provided with information as to how their premiums are loaded' (Human Genetics Commission, 2001:1). It also expressed the worry that family history information is not always interpreted appropriately in underwriting. In its final report the commission resolved to 'not at present recommend that the insurance moratorium 
currently in place in the UK should be extended to the use of family history information' (Human Genetics Commission, 2002:7.16). However, it made clear its intention to continue to consider, with the industry and others, the wider question of access to personal genetic information, including family history, in more detail during the period of the moratorium (Human Genetics Commission, 2002:7.17).

Also in the context of the current national Inquiry in Australia, attention has been focused on the continued use of family history by insurers, with specific questions being posed in the Issues Paper seeking submissions on this issue (Australian Law Reform Commission, 2001: questions 11-9, 11-11). It may at first sight seem counter-intuitive to say that the historical practice of using family history should continue, regardless of any new development in the field that would allow a more efficient practice to be followed. Further, it could be argued that if there are perceived to be problems with both, then the more accurate form of information available through genetic testing should be used.

Whilst distinguishing between genetic test and other genetic information such as family history may appear to create some anomalies, there are some grounds to argue that the risks associated with genetic test information are considerably greater than those arising from the use of family history. Through established usage of family history, there is a better understanding of its significance for underwriting purposes than is presently the case in relation to most genetic tests: as most of these are very new, there has been little opportunity for the actuarial relevance of the test information to be properly assessed. Unlike genetic test results, which are often credited with greater probative value than they warrant, family history is generally understood as lacking in precision. Notably, most of the concerns that are being raised about the use of genetic information, including claims of unfair discrimination, relate to the use of genetic test information rather than family history, and this has generally been the focus of reforms in other jurisdictions.

The justification for restricting insurers' access is greatest in respect of genetic test information, and it would be overly restrictive of insurers' underwriting practices if substantial inroads were to be made on the current position in relation to information obtained through family history. Indeed, access to family history could be argued to be necessary as a safeguard against adverse selection, and there has already been some actuarial modeling undertaken in the United States in respect of genetic testing for breast and ovarian cancer which supports this view (Subramanian et al, 1999:548-549). Accordingly, it is submitted that it is appropriate to draw a distinction between genetic tests and family history. This position reflects a pragmatic recognition that insurers have traditionally had access to family history and that precluding access to this form of information could have significant adverse selection implications for insurers.

Notably, the Inquiry Discussion Paper does not propose to change the rules in relation to insurers' access to family history information. It has, however, indicated its view that insurers, through their peak bodies, should develop industry policies on the use of family medical history in underwriting to ensure that 
discrimination based on such information is scientifically reliable and actuarially relevant (Australian Law Reform Commission, 2002:24.139).

Inevitably, questions arise challenging the validity of distinguishing genetic test information from other health information, some of which may also be predictive or particularly sensitive. It is argued that there are good reasons for singling out genetic test data in view of the greater risks associated with this kind of information. In particular, there is concern that predictive genetic test results will be misunderstood and misinterpreted, treated as having greater probative value than they deserve, resulting in unfair discrimination against individuals. Singling genetic test information out is not unfair as all comers will be treated the same in relation to that data. The fact that the impact of this may be haphazard, benefiting some more than others, does not necessarily make this approach inequitable.

Sometimes there are attempts to take the argument the other way: instead of arguing against special treatment for genetic test information, it is claimed that intervention should go further, such that there is no risk assessment on any health grounds for life/disability insurance. This can be dismissed as a Utopian ideal. Such a proposal might work if the industry was underwritten by the state or if such insurance cover were compulsory, but this sort of proposition is totally unrealistic for a system of voluntary insurance within an industry that is based on commercial principles. So, it is submitted that it is not sensible to challenge the idea of risk assessment per se, but there is justification for creating a limited exception in respect of genetic test information because this is an area where the operation of the normal insurance principles has proved to be troublesome in practice.

It has been suggested that there is a need to balance competing interests: whilst there are strong justifications for restricting insurers' access to and use of genetic test information in the interests of individuals, there is also a need to protect the insurance industry from the most costly aspects of adverse selection in respect of above average claims. Drawing on developments elsewhere, the most sensible solution would be to limit the restriction on the use of predictive genetic test results to small to average sized policies, permitting use of genetic tests where individuals are seeking large amounts of cover. In these circumstances, there will be a need for safeguards to ensure the scientific reliability and actuarial relevance of genetic information used in underwriting.

Notwithstanding considerable support for a 'two-tier' model along these lines from a range of quarters, as reflected in submissions to the Inquiry (Australian Law Reform Commission, 2002:24.67), the Inquiry has made its view clear that there should be no fundamental change to the basis of underwriting applications that involve genetic information (Australian Law Reform Commission, 2002: 24.90). It does, however, recognise that some degree of independent oversight of the use of predictive genetic test information in underwriting is needed to help ensure that the use of such information is either firmly based on actuarial or statistical data, or that it appears reasonable, in the absence of such data. To this end, the Inquiry proposes the establishment of the Human Genetics Commission of Australia (HGCA) which would be vested with the responsibility of 
determining which predictive genetic tests are appropriate for use in insurance underwriting (Australian Law Reform Commission, 2002:Proposals 3-1 to 3-7, 24-2, 24-3). It further proposes that no predictive genetic test should be used by insurers in underwriting mutually rated insurance unless the test has been approved for that purpose by the proposed HGCA (Australian Law Reform Commission, 2002:Proposal 24-3).

\section{Form of Regulation?}

If changes are to be made along the lines suggested in this paper, which go somewhat further than the reforms proposed by the joint Inquiry into the Protection of Human Genetic Information, the difficult question then arises as to how reform is best achieved: should legal or non-legal solutions be invoked to protect the community from unfair genetic discrimination? In seeking to answer this question, one should be wary of placing too much store in legal solutions: whilst the law is an important instrument to promote justice and fair treatment of individuals, one needs to be realistic about what the law can achieve. The law should not be thought of as an omnipotent force, but rather as a guiding instrument which helps to shape society. It seems logical to suggest that a multifaceted approach rather than a single pronged strategy is needed to tackle the problem of genetic discrimination, involving laws or regulations, but also committed to more focus on education, both within the industry and the wider public.

Assuming the need for some change is supported in principle, the choice would be for either a legislative approach - be it through amendment of existing legislation or the introduction of new legislation specific to genetics such as the Genetic Privacy and Non-Discrimination Bill 1998 (Cth) - or the implementation of change through non-legislative means. Each approach has some attractions but also drawbacks.

There are considerable limitations attached to a fixed legislative approach including the practical difficulty of defining, in statutory terms, the scope of operation of the legislation, and related problems of interpretation (for example, what is 'genetic disease'?). There has also been debate about the validity of distinguishing between genetic and non-genetic conditions; or between genetic and non-genetic tests, and whether these boundaries can be drawn precisely for the purposes of legislation (Alper and Beckwith, 1998:143-146). Whilst these are problems which arise with any attempt to regulate in this area, they arise most acutely in the context of legislative reform. There is also the difficulty that once enacted, a legislative solution is an inflexible instrument, limited in its capacity to respond to change in an area of rapid scientific and technological development.

These difficulties may point to less formal, more flexible non-legislative solutions, for example through the introduction of industry codes of conduct or moratoria. Such an approach would, of course, require cooperation from the relevant industry, but this may be forthcoming, particularly if the alternative is a more heavy-handed legislative response. However, reforms achieved in this way would not have the same capacity for enforcement, and are therefore likely to be 
less protective of the interests of individuals who have undergone genetic testing. Nevertheless, measures along these lines may be appropriate in the shorter term, possibly as an interim solution. Notably, in the Netherlands such measures were in place for a number of years, and were later formalised through legislation.

If there is ultimately to be a legislative response, it is important that it is well targeted, preferably along minimalist lines, modifying existing legislation where necessary. Above all, care must be taken to avoid creating a statutory monolith by way of overreaction to the problems that we are currently facing.

\section{Conclusion}

In conclusion, it is submitted that there is already enough evidence of a 'problem' to justify intervention aimed at regulating insurers' use of genetic test information. However, the response that ought to be taken is a measured, targeted response addressing those aspects of the present situation that are most problematic. This would entail limiting the use of genetic test information for small to average sized policies but permitting use of 'approved' genetic tests for the underwriting of large policies. A legislative solution should be a last resort: ideally such measures could be achieved through an industry supported moratorium as has occurred in the United Kingdom. A co-regulatory model of this kind would guarantee industry input (eg in determining the level of the threshold or ceiling) and would avoid more rigid solutions being imposed on the industry.

\section{References}

Alper, J. and Beckwith, J. (1998), 'Distinguishing Genetic and Nongenetic Medical Tests: Some Implications for Antidiscrimination Legislation,' Science and Engineering Ethics $4: 141-150$.

Australian Law Reform Commission (2001), 'Protection of Human Genetic Information', Issues Paper 26, Sydney.

Australian Law Reform Commission (2002), 'Protection of Human Genetic Information', Discussion Paper 66, Sydney.

Billings, P., M. Kohn, M. de Cuevas, J. Beckwith, J. Alper, and M. Natowicz (1992), 'Discrimination as a Consequence of Genetic Testing,' American Journal of Human Genetics 50:476-482.

Barlow-Stewart, K. and D. Keays (2001), 'Genetic Discrimination in Australia,' Journal of Law and Medicine 8:250-262.

Brom, M. (1991), 'Insurers and Genetic Testing: Shopping for that Perfect Pair of Genes,' Drake Law Review 40:121-148.

Council of Europe (1997), 'Convention for the Protection of Human Rights and Dignity of the Human Being with Regard to the Application of Biology and Medicine: Bioethics Convention on Human Rights and Biomedicine, Oveida, 4 April 1997', European Treaty 
Series No. 164, Council of Europe Publishing, Strasbourg http://www.coe.fr/eng/legaltxt/164e.htm

Council of Europe (1997), 'Convention on Human Rights and Biomediicine: Explanatory Memorandum', available at http://conventions.coe.int/Treaty?EN/CadreListeTraites.htm (listing for ETS No. 164).

Geller, L., J. Alper, P. Billings, C. Barash, J. Beckwith, and M. Natowicz (1996), 'Individual, Family, and Societal Dimensions of Genetic Discrimination: A Case Study Analysis,' Science and Engineering Ethics 2:71-88.

Harper, P. (1997), 'Genetic Testing, Life Insurance, and Adverse Selection,' Philosophical Transactions of the Royal Society of London Series B 352:1063-1066.

Holtzman, N., P. Murphy, M. Watson and P. Barr (1997), 'Predictive Genetic Testing: From Basic Research to Clinical Practice,' Science 278:602-605.

House of Commons, Select Committee on Science and Technology Committee (2001), Genetics and Insurance, Report, The Stationary Office Limited, London.

Human Genetics Advisory Commission (1997), The Implications of Genetic Testing for Insurance, Report, Human Genetics Advisory Commission, London.

Human Genetics Commission (2001), The Use of Genetic Information in Insurance Interim Recommendations, Report, Human Genetics Commission, London, http://www.hgc.gov.uk.

Human Genetics Commission (2002), Inside Information: Balancing Interests in the Use of Personal Genetic Data, Report, Human Genetics Commission, London, http://www.hgc.gov.uk

Human Rights and Equal Opportunity Commission (1998), Disability Standards and Guidelines: Guidance for Providers of Insurance and Superannuation, Human Rights and Equal Opportunity Commission, http://www.humanrights.gov.au/disability_rights/

Investment and Financial Services Association Ltd (2002), Genetic Testing Policy, Standard No. 11.00, January.

Institute of Actuaries of Australia (2001), 'Genetics in Society', Paper prepared for presentation at the Institute of Actuaries of Australia 2001 Biennial Convention.

Institute of Actuaries of Australia (2002), IFSA Genetic Test Survey Report (Period Three: 1 December 2001-31 May 2002), Report, Institute of Actuaries of Australia.

Lapham, E., C. Kozma and J. Weiss, (1996), 'Genetic Discrimination: Perspectives of Consumers,' Science 274:621-624.

Low, L., S. King, and T. Wilkie (1998), 'Genetic Discrimination in Life Insurance: Empirical Evidence for a Cross Sectional Survey of Genetic Support Groups in the United Kingdom,' British Medical Journal 317:1632-1635.

Macdonald, A. (1997), 'How Will Improved Forecasts of Individual Lifetimes Affect Underwriting?,' Philosophical Transactions of the Royal Society of London, Series B, 352:1067-1075. 
Macdonald, A. (1999), 'Modeling the Impact of Genetics in Insurance,' North American Actuarial Journal 3:83-105.

Nuffield Council on Bioethics (1993), Genetic Screening: Ethical Issues, Report, London

O’Neill, O. (1998), 'Insurance and Genetics: The Current State of Play,' Modern Law Review 61:716-723.

Otlowski, M. (2000), 'Resolving the Conundrum: Should Insurers be Entitled to Have Access to Genetic Test Information?,' Insurance Law Journal 11:193-215.

Otlowski, M. (2001), 'Avoiding Genetic Testing and Insurance: An Exploration of the Legality and Ethics of Precautionary Measures in Anticipation of Unfavourable Test Outcomes,' Monash Bioethics Review 20: 24-32.

Otlowski, M., S. Taylor, and K. Barlow-Stewart (2002), 'Major Study Commencing into Genetic Discrimination in Australia,' Journal of Law and Medicine 10:41-48.

Pokorski, R. and U. Ohlmer (2000), 'Use of a Markov Model to Estimate Long Term Care Insured Lives: Mortality Risk Associated with BRCA1 \& BRCA2 Mutations', North American Actuarial Journal 4:130-148.

Subramanian, K. J. Lemaire, J. Hershey, M. Pauly, K. Armstrong and D. Asch (1999), 'Estimating Adverse Selection Costs from Genetic Testing for Breast and Ovarian Cancer: The Case of Life Insurance', Journal of Risk Insurance 66: 531-550.

Trowbridge Consulting (1993), HIV/AIDS, Superannuation and Insurance, Sydney.

United Nations Educational, Scientific and Cultural Organization, Universal Declaration on the Human Genome and Human Rights (adopted by the General Conference of UNESCO in November 1997),

Wertz, D. (1998), 'Genetic Discrimination: Results of a Survey of Genetics Professionals, Primary Care Physicians, Patients and Public', Health Law Review 7:7-8.

World Health Organisation (1997), Proposed International Guidelines on Ethical Issues in Medical Genetics and Genetic Services: Report of a WHO Meeting on Ethical Issues in Medical Genetics, Geneva, 15-16 December 1997, World Health Organisation, Human Genetics Programme, Geneva, http://www.who.int/ncd/hgn/hgnethic.htm.

This article is based on a paper presented at a recent conference on Genetics and Financial Services organised by the Centre for Actuarial Research at the ANU'S School of Finance and Applied Statistics, the Institute of Actuaries and the Securities Institute. The author would like to extend her thanks to the two anonymous reviewers for their helpful comments. 